\title{
Categorization of profiles of the vehicles intelligently and automatically at Toll Plaza's
}

\author{
Swati Kadlag \\ Symbiosis Institute of Technology, Lavale, Pune.
}

\begin{abstract}
Toll Plaza or check posts on the highways where continuous toll collection takes place by the persons appointed for its collection from the owners of the vehicles. It is intended by the user of this application to make oneself able to verify, "Is the person collecting the amount according to specified class of the vehicle or not? "It is useful for the auditors for verification of collected toll and vehicles passed.
\end{abstract}

Keywords - Region of interest, Marker image, region growing.

\section{INTRODUCTION}

The basic requirement of obtaining minimum clean and clear image can be applied to the thought process which at present is implemented by the system on the toll plaza by obtaining and storing images of the vehicle in its database with the help of sensor array of trans receiver system implemented on the plaza.

User of this application require these images of vehicles should be identified by the classification algorithm or program for which, the part of images which is of no interest must be removed and the image should be in such a way that with the help of result one will be able to conclude that amount of toll collected by the authorized person is valid according to the Class of vehicle.

Before classifying the vehicles into various categories the basic requirement is there should be minimum clean image input to classifying algorithm. That mean the images should be filtered or extra back trails present in the background for better human perception and better machine interpretation. Methods subjected to this issue are as follows

\section{A. IMAGE SEGMENTATION}

\section{Threshoulding}

We can set threshold $\mathrm{T}$, so at any point $\mathrm{f}(\mathrm{x}, \mathrm{y})>=\mathrm{T}$ is called object point ;otherwise point is called as background point. The thresholded image is defined as

$$
\begin{aligned}
g(x, y)= & \{1 \text { if } f(x, y)>=1 \\
& 0 \text { if } f(x, y)<1
\end{aligned}
$$

Pixels labelled 1 correspond to objects, pixels labelled zero correspond to the background ${ }^{[1]}$. Two types of thresholds are

1.1.1 Global threshold - When threshold $\mathrm{T}$ is constant and applied to complete image. Then the approach is called as global thresholding ${ }^{[1]}$.

1.1.2. Local or Adaptive thresholding - global segmentation fails when illumination is uneven. In such cases its required to preprocess the image to compensate for illumination and then apply a global threshold to preprocessed image. This is equivalent to thresholding $f(x, y)$ with a locally varying threshold function. This allows selecting different values of threshold according to the properties of image input with the help of graphical control and can see the result immediately ${ }^{[3]}$. The new result image $\mathrm{g}(\mathrm{x})$ is now

Where $\mathrm{T}(\mathrm{x}, \mathrm{y})=F 0(\mathrm{x}, \mathrm{y})+\mathrm{T} 0$

$$
\begin{aligned}
g(x, y)= & \{1 \text { if } T(x, y)>=1 \\
& 0 \text { if } T(x, y)<1
\end{aligned}
$$

1.2. Region based segmentation: - The objective of region based segmentation is partition an image into regions. We can approach this problem by finding boundaries between regions based on discontinuities in the intensity levels etc. Entire image can be partitioned using 
1.2.1. Basic formulation:- This uses some logical predicate to set $\mathrm{P}(\mathrm{Ri})=\mathrm{TRUE}$ and $\mathrm{i}=1,2,3 . \mathrm{n}$, such that partitions region $\mathrm{R}$ into $\mathrm{n}$ sub regions $\mathrm{R} 1, \mathrm{R} 2, \mathrm{R} 3, \mathrm{R} 4 \ldots . . \mathrm{R} \mathrm{n}^{[1]}$.

1.2.2. Region growing :- By using region growing procedure one can group the pixels or sub region into larger region based on predefined criteria or mentioned specific properties of image. And the procedure of growing of the region should stop as soon as there are no more pixels satisfying the specified criteria.

\section{B. IMAGE FILLING -}

In the next scheduled meeting it was discussed that one can see if edge detection can be applied in the way- scan the image on the edge of vehicle or desired object wherever extra trails or horizontal lines are present at start of image and after the vehicle ${ }^{[3]}$.

-One can check the various intensity pixels on the edge if light intensity pixels are present on both the side then by checking the continuity of equal intensity of side pixels and decision for their removal is affordable.

-If line is totally disconnected from the body vehicle then that definitely it is the trail in the background.

-Another approach discussed was filling the intense part of the vehicle in the image so that probability of removal of part of interest in the image gets reduced. This demands us to use of image filling. This fills the region of interest (ROI) by interpolating pixel values from boarders of the region according to their connectivity with each other. Following figure elaborate the process and result of same.

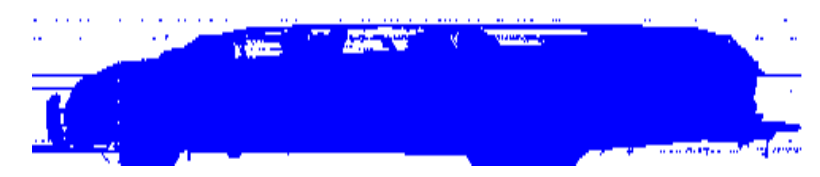

Fig . 1 Original Image available Source: Rajdeep Infotechno Ltd, Pune

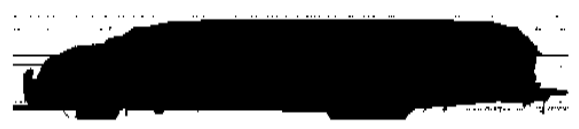

Fig.2 Filled image

\section{IMAGE FILTERING -}

Image filtering works in spatial domain directly on pixel values and their connectivity with neighbouring pixels. At any point $\mathrm{p}(\mathrm{x}, \mathrm{y})$, response of imfilter operation is sum of product of [filter coefficient *corresponding neighbourhood pixels in the area spanned by the filter mask]. If the neighbourhood or filter mask is of the size $\left(\mathrm{m}^{*} \mathrm{n}\right), \mathrm{m}$ and $\mathrm{n}$ coefficients are required. The coefficients $\mathbf{m}$ and $\mathbf{n}$ are arranged in a matrix. For a mask having size $m * n$, we assume typically that $\mathbf{m}=\mathbf{2} \mathbf{a}+\mathbf{1}$ and $\mathbf{n}=\mathbf{2} \mathbf{b}+\mathbf{1}$, where $\mathbf{a}$ and $\mathbf{b}$ are nonnegative integers. Principle focus is always on odd sizes due to their unique centre point. It refers either to correlation or convolution ${ }^{[2]}$.

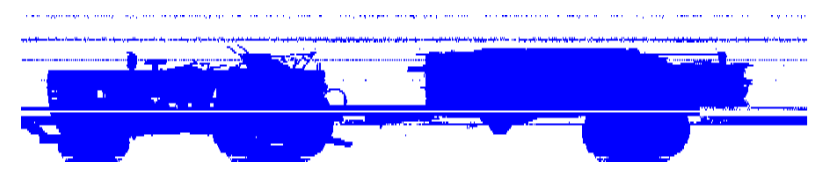

Fig. 3 Image before filtering Source: Rajdeep Infotechno Ltd, Pune 


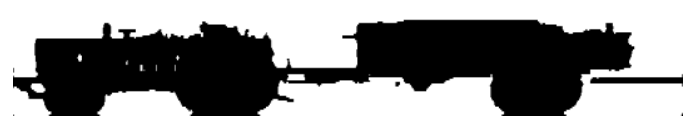

Fig.4 Result of filtering

\section{PRESERVING INTERNAL DETAILS OF THE VEHICLE-}

At the time of filtering, the image is first of all filled but later on it was the prime requirement that the filled part should be recovered with the missed details and also maintains the tyre profile as it is. This stringent requirement was about to force not to use the filling operation and try to filter the unwanted trails ${ }^{[8]}$.

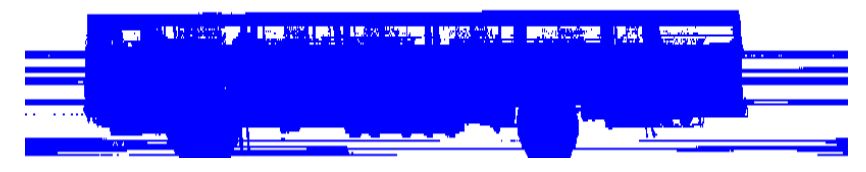

Fig. 5. Image before filtering and thinning Source: Rajdeep Infotechno Ltd, Pune

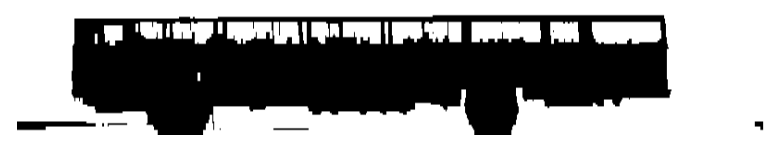

Fig. 6 . Result of thinning

\section{E. CATEGORIZATION OF VEHICLES -}

Various types of algorithms and transforms are helping to direct and indirect categorization of the monochrome images.

Hough transform is one out of those all and gradient filters to name the few are sobel, prewitt and canny. Using above method Skelton of the vehicle. And finally transforms leads to categorization. Following figures elaborates the result of categorizing commercial motor vehicle ${ }^{[5]}$.

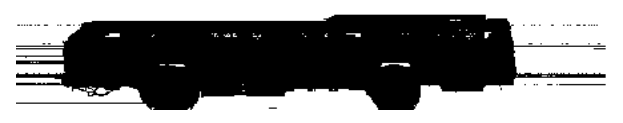

Fig .7 Image for categorization. Source: Rajdeep Infotechno Ltd, Pune

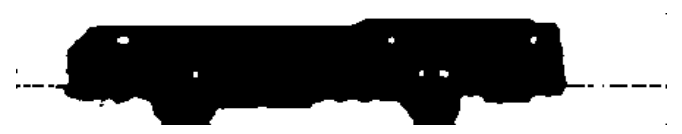

commercial Motor vehicle

Fig .8 Categorized Image

www.iosrjournals.org

$10 \mid$ Page 


\section{CONCLUSION}

Along with filling and filtering operations when it became the priority work to maintain the internal profile or passenger profile of the vehicle then thinning or skeltonizing is used to serve the purpose. Finally particular vehicle passing is successfully categorized.

\section{ACKNOWLEDGEMENT}

I feel immense pleasure in taking this opportunity of expressing my sincere indebtedness and deep sense of gratitude to Prof. N.B.Sambre, KIT COE Shivaji University and Prof. Manish Patil, Project Manager, Rajdeep infotechno Ltd for their valuable advice, constant guidance, help and support in all respects, inspiration and constructive criticism. And would like to pay my sincere thanks to Mr. Jay Kharade, Rajdeep infotechno pvt ltd, pune, for permitting to work in the company premises along with all technical support, guidance and required inputs.

\section{REFERENCES}

[1] Rafael C.Gonzalez and Richard E. Woods, "Digital Image Processing, Pearson Education", 2004.

[2] Rafael C.Gonzalez and Richard E. Woods and Steven L. Eddins," Digital Image Processing with MATLAB", Pearson Education", 2006.

[3] Delores M.Etter, David C.Kuncicky and Doug Hull," Introduction to MATLAB”, Pearson Education”, 2006.S.

[4] Chapman Stephan,"MATLAB programming for Engineers", second edition, International student edition, Thomson books

[5] E. J. Delp and O. R. Mitchell. Image coding using block truncation coding. IEEE Trans. Commun., 27:1335.1342, 1979.

[6] IEEE journal of,"Selected Topics In signal processing", October 2009, Volume-3,No-5.

[7] IETE journal of research, "special issue on biomedical image and signal processing", Volume 54, No-3

[8] T. Chen and H. R. Wu. Impulse noise removal by multi-state median_filtering. In Proc. IEEE Int. Conf. on Acoustics, Speech, and Signal Processing, volume IV, pages 2183.2186, June 2000.

[9] John Canny. A computational approach to edge detection. IEEE Trans. Pattern Analysis and Machine Intelligence, PAMI8(6):679.698, November 1986.

[10] http://www.eee.bham.ac.uk/spannm/computervision/image segmentation 